\title{
Salvage surgery to treat tumor regrowth after stereotactic body radiotherapy in primary non-small cell lung cancer
}

\author{
Takahisa Koizumi ${ }^{1}$, Tadashi Aoki ${ }^{2}$, Masayuki Saito ${ }^{3}$, Yasushi Yamato ${ }^{4}$, Go Furuyashiki ${ }^{5}$, Akihiko Kitahara ${ }^{6}$, \\ Takehisa Hashimoto $^{7}$, Takehiro Watanabe ${ }^{1}$, Masanori Tsuchida ${ }^{8}$; for the Niigata Chest Surgery Research \\ Group
}

${ }^{1}$ Department of Thoracic Surgery, National Hospital Organization Nishi-Niigata Chuo National Hospital, Niigata, Japan; ${ }^{2}$ Division of Chest Surgery, Niigata Cancer Center Hospital, Niigata, Japan; ${ }^{3}$ Department of Thoracic Surgery, Niigata Prefectural Central Hospital, Joetsu, Niigata, Japan; ${ }^{4}$ Department of Thoracic Surgery, Japanese Red Cross Nagaoka Hospital, Nagaoka, Niigata, Japan; ${ }^{5}$ Department of Thoracic Surgery, Nagaoka Chuo General Hospital, Nagaoka, Niigata, Japan; ${ }^{6}$ Department of Thoracic Surgery, Niigata Prefectural Shibata Hospital, Shibata, Niigata, Japan; ${ }^{7}$ Department of Thoracic Surgery, Uonuma Kikan Hospital, Uonuma, Niigata, Japan; ${ }^{8}$ Division of Thoracic and Cardiovascular Surgery, Niigata University Graduate School of Medical and Dental Sciences, Niigata, Japan

Contributions: (I) Conception and design: T Koizumi, T Aoki; (II) Administrative support: T Watanabe, M Saito, M Tsuchida; (III) Provision of study materials or patients: All authors; (IV) Collection and assembly of data: T koizumi; (V) Data analysis and interpretation: All authors; (VI) Manuscript writing: All authors; (VII) Final approval of manuscript: All authors.

Correspondence to: Takahisa Koizumi, MD. Department of Thoracic Surgery, National Hospital Organization Nishi-Niigata Chuo National Hospital, 1-14-1 Masago, Nishi-ku, Niigata city, Niigata, Japan. Email: t.koizumi@me.com.

Background: Stereotactic body radiotherapy (SBRT) is considered to be an effective and safe treatment in patients with primary lung cancer. If local recurrence is confirmed following SBRT, surgical treatment is a possibility. The present study aimed to clarify the safety and survival outcomes of salvage surgery in primary lung cancer patients with local recurrence following SBRT.

Methods: All subjects were patients with primary lung cancer who underwent surgical treatment for local recurrence following SBRT during the period from July 2005 to July 2015. We evaluated the reason for SBRT selection, the surgical procedure, postoperative complications, and prognosis.

Results: Of 932 patients underwent SBRT as treatment for primary lung cancer, 48 patients $(5.2 \%)$ had local recurrence alone and 19 patients (2.0\%) underwent salvage surgery. SBRT was selected in eight medically operable patients who refused surgery, and in 11 patients considered medically inoperable by their pulmonologist. Lobectomy was performed in 15 patients. Postoperative complications were documented in 4 patients $(21.1 \%)$. Incomplete resection was performed in 2 patients. Stage progression was confirmed in 7 patients (36.8\%). The 5 -year overall survival (OS) was $72.5 \%$ and the 5 -year disease-free survival (DFS) was $65.2 \%$.

Conclusions: We evaluated patients who underwent salvage surgery due to local recurrence of lung cancer following SBRT. We found that salvage surgery could be performed safely without affecting SBRT outcomes. We further infer that cases of complete resection are likely to be associated with good prognosis, and that SBRT should be selected only after careful consideration because complete resection is not possible in all cases.

Keywords: Lung cancer; stereotactic body radiotherapy (SBRT); salvage surgery

Submitted Jun 20, 2020. Accepted for publication Sep 16, 2020.

doi: $10.21037 /$ jtd-20-2253

View this article at: http://dx.doi.org/10.21037/jtd-20-2253 


\section{Introduction}

Stereotactic radiotherapy was developed as a high-precision radiation technique for the treatment of intracranial tumors. In the late 1990s, stereotactic body radiotherapy (SBRT) was made possible because of image-guided radiation delivery techniques and the development of tumor motion management. Accordingly, this therapy has been applied to lung tumors. Currently, SBRT is considered to be an effective and safe treatment in patients with medically inoperable primary lung cancer (1-5), and the number of such treatments is increasing with increase in the number of SBRT-capable facilities. Recent reports have shown that the local control rate was $90 \%$ or more over three years in patients with early-stage primary lung cancer undergoing SBRT $(1,2)$. However, the number of cases with cancer recurrence following SBRT resulting in surgical treatment (in cases with no metastasis and medically operable patients) have increased in recent years (6-9).

The present study aimed to retrospectively analyze the safety of salvage surgery in patients with local recurrence following SBRT, evaluating survival outcomes and discussing the current problems associated with this treatment. We present the following article in accordance with the STROBE reporting checklist (available at http:// dx.doi.org/10.21037/jtd-20-2253).

\section{Methods}

\section{Study design}

This study protocol complied with the Declaration of Helsinki (as revised in 2013). The institutional review board approved this study (approval No. 1909) and waived the requirement for informed consent because the study was a retrospective review.

All subjects were patients with primary lung cancer who underwent surgical treatment for local recurrence following SBRT at eight institutions for the Niigata Chest Surgery Research Group during the period from July 2005 to July 2015 . The patients were followedup by a radiation oncologist and a pulmonologist after SBRT, and if recurrence was suspected, the patients were referred for assessment of the possibility of salvage surgery. Local recurrence was defined as tumor regrowth seen on computed tomography (CT) scans. In addition, positron emission tomography-CT was used for supplementary diagnosis if local recurrence was suspected on CT scans. During recurrence, if the patients had no lymph node or distant metastasis, and were examined to be medically operable, surgical treatment was performed with their written consent.

Patients who were surgically treated for local recurrence following SBRT were evaluated. The data collected included the reason for SBRT selection, the time period from SBRT to salvage surgery, tumor diameter, surgical procedure, postoperative complications, and prognosis. All complications were classified into four grades of postoperative complications as per Clavien-Dindo classification criteria (10).

Each patient underwent blood tests including serum tumor marker tests and radiological examinations. A chest $\mathrm{X}$-ray was performed every 2-3 months, and chest CT scans were performed every six months. Similar to usual lung cancer follow-up, the diagnosis of recurrence was confirmed based on clinical symptoms, radiologic findings, and pathological findings. An observation was censored at the last follow-up visit when the patient had either died without recurrence or was lost to follow-up.

\section{Statistical analysis}

Overall survival (OS) was defined as the time from the day of salvage surgery to the day of death or the end of followup, with disease-free survival (DFS) defined as the time from the day of salvage surgery to the day of recurrence or the end of follow-up. Cumulative survival rates were calculated by the Kaplan-Meier method. Survival differences were compared using the log-rank test. Differences showing a value of $\mathrm{P}<0.05$ were considered significant. SPSS for Windows version 24 (SPSS Japan, an IBM company, Tokyo, Japan) was used for the statistical analyses.

\section{Results}

A total of 932 patients underwent SBRT as treatment for primary lung cancer during the period from July 2005 to July 2015 (Figure 1). Before SBRT, 511 (54.8\%) patients had histological 87 confirmation, and the remaining 421 patients 88 were clinically diagnosed with primary lung cancer on 89 radiographic imaging. Of these, 81 patients $(8.7 \%)$ were found to have lung cancer recurrence and 48 patients $(5.2 \%)$ had local recurrence alone. Nineteen patients $(2.0 \%)$ underwent salvage surgery, and none of them were evaluated by a thoracic surgeon before SBRT. The characteristics of the patients are shown in Table 1. The reasons for SBRT selection were surgery refusal by eight 


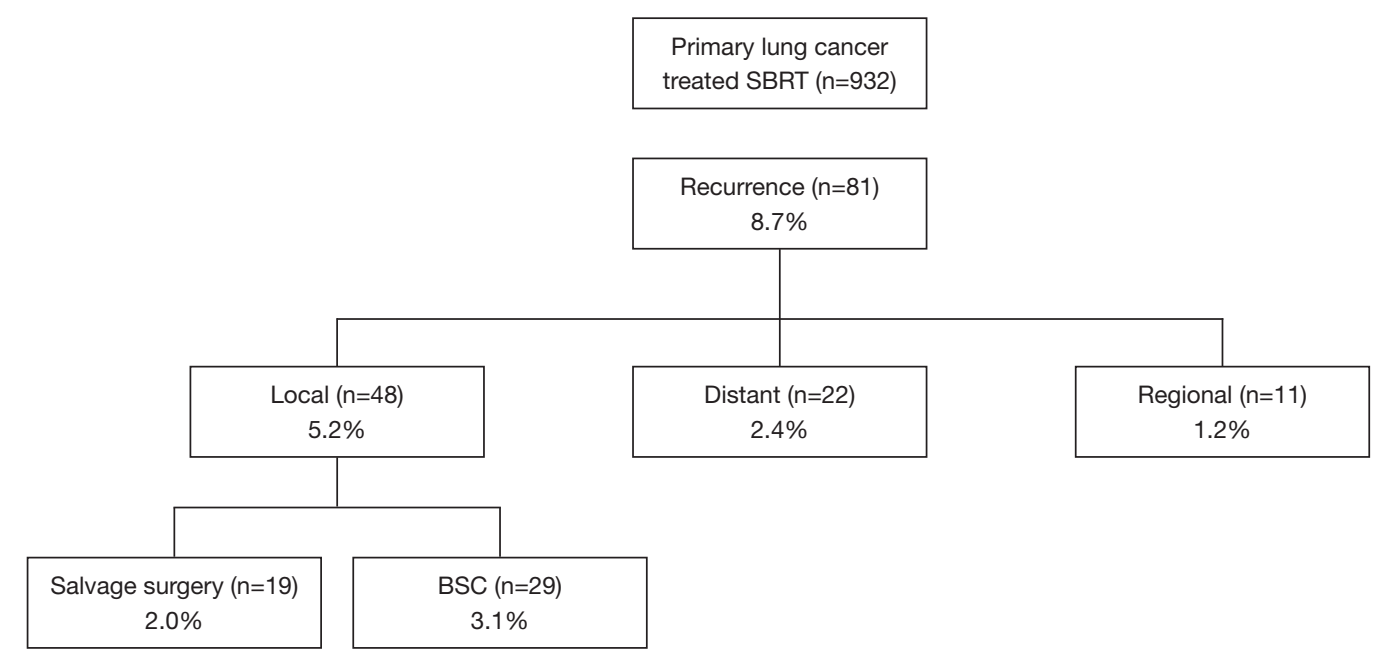

Figure 1 Patterns of disease recurrence after stereotactic body radiotherapy for non-small-cell lung cancer. SBRT, stereotactic body radiotherapy; BSC, best supportive care.

Table 1 Patient characteristics at SBRT

\begin{tabular}{|c|c|}
\hline Variable & Value \\
\hline Age (years) & 77 [59-83] \\
\hline Gender (M/F) & $18 / 1$ \\
\hline \multicolumn{2}{|c|}{ Performance status (ECOG) } \\
\hline 0 & 10 \\
\hline 1 & 9 \\
\hline \multicolumn{2}{|l|}{ Reason for SBRT } \\
\hline Patient's choice & 8 \\
\hline Inoperable & 11 \\
\hline Old age & 5 \\
\hline COPD & 3 \\
\hline Comorbidities & 3 \\
\hline \multicolumn{2}{|l|}{ Histology } \\
\hline Squamous cell & 15 \\
\hline Adenocarcinoma & 4 \\
\hline \multicolumn{2}{|l|}{ yc-Stage } \\
\hline T1aNOMO & 7 \\
\hline T1bNOMO & 9 \\
\hline T2aNOMO & 3 \\
\hline Tumor size (mm) & 23 [12-48] \\
\hline
\end{tabular}

SBRT, stereotactic body radiotherapy. medically operable patients during initial evaluation, and medically inoperable status of eleven patients as judged by their pulmonologist because they were elderly $(n=5)$, had low pulmonary function $(\mathrm{n}=3)$, or had other comorbidities $(\mathrm{n}=3)$. Histologically, 15 patients were diagnosed with squamous cell carcinoma and four patients were diagnosed with adenocarcinoma. The patient characteristics at time of surgery are shown in Table 2. The median (range) time period from SBRT to salvage surgery was 17.3 (7.6-58.3) months, the tumor size increased from a median of $23[12-48] \mathrm{mm}$ at SBRT to $38[15-55] \mathrm{mm}$ at the time of recurrence.

None of the patients showed intrapleural adhesion due to SBRT during salvage surgery. Complete resection was performed in 17 patients and incomplete resection was performed in two patients. In those with incomplete resection, one patient was found to have malignant pleural effusion and the other patient was found to have descending aorta invasion during surgery. Lobectomy was performed in 15 patients (pneumonectomy with aortic resection in one patient), segmentectomy in three patients, and wedge resection in one patient. Lymph node dissection was performed in all patients, except for the one who underwent wedge resection, and pathology examinations showed lymph node metastasis in two patients (Tables 3,4).

Postoperative complications were documented in 4 patients $(21.1 \%)$, including prolonged air leak (more than 
Table 2 Patient characteristics at time of surgery

\begin{tabular}{|c|c|}
\hline Variable & Value \\
\hline Interval from SBRT to surgery (months) & $17.3(7.6-58.3)$ \\
\hline \multicolumn{2}{|l|}{ Diagnostic imaging } \\
\hline CT & 9 \\
\hline PET-CT & 10 \\
\hline Tumor size at recurrence (mm) & 38 [15-55] \\
\hline \multicolumn{2}{|l|}{ yc-Stage } \\
\hline T1aN0M0 & 3 \\
\hline T1bNOM0 & 4 \\
\hline T2aNOMO & 8 \\
\hline T2bNOMO & 3 \\
\hline T3NOMO & 1 \\
\hline \multicolumn{2}{|l|}{ Surgical procedure } \\
\hline $\begin{array}{l}\text { Lobectomy [pneumonectomy with } \\
\text { aortic resection] }\end{array}$ & $\begin{array}{l}15[1] ; \text { aortic } \\
\text { invasion: } 1\end{array}$ \\
\hline Segmentectomy & 3; aortic invasion: 1 \\
\hline Wedge resection & 1 \\
\hline \multicolumn{2}{|l|}{ Operative findings } \\
\hline Aortic invasion & 2 \\
\hline Malignant pleural effusion & 1 \\
\hline \multicolumn{2}{|l|}{ Postoperative complication } \\
\hline Pulmonary fistula & 2 \\
\hline Heart failure & 1 \\
\hline Pleuritis & 1 \\
\hline Tumor size at surgery (mm) & $28[15-47]$ \\
\hline \multicolumn{2}{|l|}{ p-Stage } \\
\hline T1aNOMO & 1 \\
\hline T1bNOM0 & 8 \\
\hline T2aNOMO & 6 \\
\hline T2aN2M0 & 1 \\
\hline T4NOMO & 1 \\
\hline T4N1M0 & 1 \\
\hline T2aN2M1a & 1 \\
\hline Observation period (months) & $30.2(9.4-120.1)$ \\
\hline \multicolumn{2}{|l|}{ Outcome } \\
\hline Alive & 8 \\
\hline Alive with recurrence & 4 \\
\hline cancer death & 3 \\
\hline Death due to other disease & $\begin{array}{l}4 \text { (other cancer: } 2 \text {; } \\
\text { pneumonia: 2) }\end{array}$ \\
\hline
\end{tabular}

SBRT, stereotactic body radiotherapy.
5 days) in two patients, pleuritis in one, and heart failure in the other. The Clavien-Dindo scores were I or II in all 4 patients.

Over a median follow-up period of 34.8 months in patients who underwent salvage surgery, The 5 -year OS and DFS was $72.5 \%$ and $65.2 \%$, respectively (Figure $2 A, B$ ). The 3 -year OS in patients with lobectomy and limited resection after SBRT were $84.6 \%$ and $0 \%$, respectively $(\mathrm{P}=0.039)$, and the 3 -year DFS were $65.6 \%$ and $0 \%$, respectively $(\mathrm{P}=0.853)$ (Figure $2 C, D)$. In addition, eight patients survived without recurrence, four patients survived with recurrence, three patients died from recurrence, and 4 patients died from other diseases ( 2 from other cancers and 2 from pneumonia).

Of the four patients who survived with recurrence, two underwent a second SBRT. One of these patients had isolated pleural nodule recurrence, and the other had bronchial stump recurrence. The third patient had isolated contralateral lung metastasis recurrence, resulting in lung resection. The fourth patient who survived with recurrence experienced brain metastasis, had an epidermal growth factor receptor (EGFR) mutation, and received EGFRtyrosine kinase inhibitor therapy. Three patients died from lung cancer recurrence; one patient underwent wedge resection, one had lymph node metastasis, and the other one underwent incomplete resection because of a descending aortic invasion.

\section{Discussion}

As previously demonstrated, SBRT therapy results in high local cancer control rates and low toxicity in medically inoperable patients with early stage, nonsmall cell lung cancer (1-5). However, the definition of "medically inoperable" differs based on facilities and research, and no clear criteria have been outlined. In the present study, 19 patients underwent salvage surgery to treat local recurrence following SBRT. Of these, 11 were diagnosed to be medically inoperable by a pulmonologist (no thoracic surgeon made diagnoses in this regard). To objectively determine the status of medical operability, careful consideration by a multidisciplinary tumor board is required (6).

Although SBRT results in a high local control rate, lung cancer recurrence can occur. In the present study, 932 patients underwent SBRT; of these, 81 patients $(8.7 \%)$ were found to have lung cancer recurrence and 48 patients (5.2\%) had local recurrence alone. Senthi et al. (11) reported a local 
Table 3 Patient demographics

\begin{tabular}{|c|c|c|c|c|c|c|c|c|}
\hline Case & Age $(y)$ & Gender & Reason for SBRT & Histology & cTNM & Tumor size at SBRT (mm) & DFI (Mo) & Tumor size $(\mathrm{mm})$ \\
\hline 2 & 60 & M & COPD & $\mathrm{Sq}$ & T1bNOM0 & 22 & 10.8 & 48 \\
\hline 3 & 83 & M & High age & $\mathrm{Sq}$ & T2aNOMO & 46 & 7.6 & 35 \\
\hline 4 & 81 & M & Patient's choice & $\mathrm{Sq}$ & T1bNOM0 & 23 & 28.3 & 31 \\
\hline 6 & 68 & M & Comorbidity & $\mathrm{Sq}$ & T1bN0M0 & 25 & 26.2 & 45 \\
\hline 7 & 80 & M & Comorbidity & $\mathrm{Sq}$ & T1bN0M0 & 26 & 14.5 & 55 \\
\hline 8 & 78 & M & Patient's choice & $\mathrm{Sq}$ & T1bN0M0 & 24 & 13.3 & 31 \\
\hline 9 & 83 & M & High age & $\mathrm{Sq}$ & T2aNOMO & 48 & 8.5 & 52 \\
\hline 12 & 86 & $M$ & Patient's choice & Ad & T1bN0M0 & 26 & 58.3 & 38 \\
\hline 13 & 80 & M & Patient's choice & $\mathrm{Sq}$ & T1aNOMO & 13 & 50.3 & 42 \\
\hline 14 & 83 & $M$ & High age & Ad & T1aNoM0 & 16 & 20 & 51 \\
\hline 15 & 74 & M & Patient's choice & $\mathrm{Sq}$ & T2aNOMO & 37 & 10.8 & 31 \\
\hline 16 & 83 & $M$ & Patient's choice & $\mathrm{Sq}$ & T1aNoMo & 16 & 31.4 & 38 \\
\hline 17 & 85 & $M$ & High age & Ad & T1bNOM0 & 27 & 25 & 42 \\
\hline 18 & 67 & $M$ & Patient's choice & $\mathrm{Sq}$ & T1aNoM0 & 16 & 9.5 & 26 \\
\hline 19 & 77 & $M$ & Patient's choice & $\mathrm{Sq}$ & T1aNOMO & 12 & 36 & 45 \\
\hline
\end{tabular}

SBRT, stereotactic body radiotherapy; DFI, disease-free interval; M, male; F, female; COPD, chronic obstructive pulmonary disease; Sq, squamous cell carcinoma; Ad, adenocarcinoma.

recurrence rate of $4.9 \%$ in patients with stage T1-2 nonsmall cell lung cancer (NSCLC) at 2 years, and Lagerwaard et al. (12) reported a local recurrence rate of $5.1 \%$ in medically operable patients with stage I NSCLC at three years. Similarly, a recurrence rate of $5.2 \%$ was obtained in the present study.

Recently, the number of reports on salvage surgery to treat local recurrence following SBRT has been increasing (6-9). As in the present study, a few instances of adhesion have been previously reported due to the effect of SBRT. In the present study, surgical treatment for local recurrence following SBRT resulted in a 5-year survival rate of $72.5 \%$ in cases of complete resection. At the time of suspected local recurrence following SBRT, if the patients are diagnosed as being medically operable, aggressive salvage surgery should be considered because complete resection can result in good long-term prognosis.

The current standard treatment for stage I primary lung cancer is lobectomy and mediastinal lymph node dissection. Surgical treatment for lung cancer has a perioperative mortality of $0.7-1.4 \%$ and has been established as the treatment of choice (13-15). In addition to a high local control rate, SBRT is associated with no serious complications and very few cases of treatment-related death $(<0.0-0.7 \%)$, and is recognized as a minimally invasive treatment $(12,13)$. Therefore, SBRT may be selected in the absence of careful consideration or because of patient refusal to undergo surgery. In recent years, the number of reports regarding SBRT to treat medically operable patients with lung cancer has been increasing $(12,16)$. However, few reports have shown successful outcomes of SBRT over more than three years, whereas others have reported insufficient long-term outcomes; therefore, SBRT has not been used as a definitive treatment (17) and cannot be used as a standard of care in medically operable patients with lung cancer.

Before the introduction of SBRT, limited surgery was 
Table 4 Surgical procedures and postoperative outcomes

\begin{tabular}{|c|c|c|c|c|c|c|c|c|}
\hline Case & $\begin{array}{l}\text { Lobectomy or } \\
\text { limited surgery }\end{array}$ & Findings & $\begin{array}{l}\text { Postoperative } \\
\text { complications }\end{array}$ & $\begin{array}{l}\text { Clavien-Dindo } \\
\text { classification }\end{array}$ & pTNM & $\begin{array}{l}\text { Tumor size in } \\
\text { history (mm) }\end{array}$ & Outcome & Recurrence \\
\hline 1 & $\begin{array}{l}\text { Right upper } \\
\text { lobectomy }\end{array}$ & - & - & - & T1bNOMO & 24 & $\begin{array}{l}\text { Alive with } \\
\text { recurrence }\end{array}$ & Lung metastasis \\
\hline 2 & $\begin{array}{l}\text { Right upper } \\
\text { lobectomy }\end{array}$ & - & - & - & T1bNOMO & 28 & Alive & - \\
\hline 4 & $\begin{array}{c}\text { Right S6 } \\
\text { segmentectomy }\end{array}$ & - & - & - & T1bNOMO & 30 & $\begin{array}{c}\text { Death from other } \\
\text { disease }\end{array}$ & - \\
\hline 5 & $\begin{array}{l}\text { RUL wedge } \\
\text { resection }\end{array}$ & - & - & - & T1bNOMO & 28 & Cancer death & Local recurrence \\
\hline 8 & $\begin{array}{l}\text { Right upper } \\
\text { lobectomy }\end{array}$ & - & - & - & T1bNOMO & 25 & $\begin{array}{l}\text { Alive with } \\
\text { recurrence }\end{array}$ & $\begin{array}{l}\text { Pleural } \\
\text { metastasis }\end{array}$ \\
\hline 9 & $\begin{array}{l}\text { Left upper division } \\
\text { segmentectomy }\end{array}$ & Aortic invasion & - & - & T4NOMO & 40 & Cancer death & $\begin{array}{l}\text { Incomplete } \\
\text { resection }\end{array}$ \\
\hline 10 & $\begin{array}{l}\text { Right lower } \\
\text { lobectomy }\end{array}$ & - & - & - & T2aNOMO & 26 & Alive & - \\
\hline 11 & $\begin{array}{l}\text { Left upper } \\
\text { lobectomy }\end{array}$ & - & - & - & T1aNoMo & 15 & Alive & - \\
\hline 15 & $\begin{array}{l}\text { Right upper } \\
\text { lobectomy }\end{array}$ & - & - & - & T1bNOMO & 22 & Alive & - \\
\hline 16 & $\begin{array}{l}\text { Left upper } \\
\text { lobectomy }\end{array}$ & - & Pleuritis & II & T1bNOMO & 25 & Alive & - \\
\hline 17 & $\begin{array}{l}\text { Right middle and } \\
\text { lower lobectomy }\end{array}$ & - & - & - & T2aN2M0 & 28 & $\begin{array}{l}\text { Alive with } \\
\text { recurrence }\end{array}$ & $\begin{array}{c}\text { Brain } \\
\text { metastasis }\end{array}$ \\
\hline 18 & $\begin{array}{c}\text { Right S6 } \\
\text { segmentectomy }\end{array}$ & - & - & - & T1bNOMO & 22 & Alive & - \\
\hline 19 & $\begin{array}{l}\text { Left } \\
\text { pneumonectomy } \\
\text { with aortic resection }\end{array}$ & Aortic invasion & - & - & T4N1M0 & 45 & Alive & - \\
\hline
\end{tabular}

RUL, right upper lobe. 
A

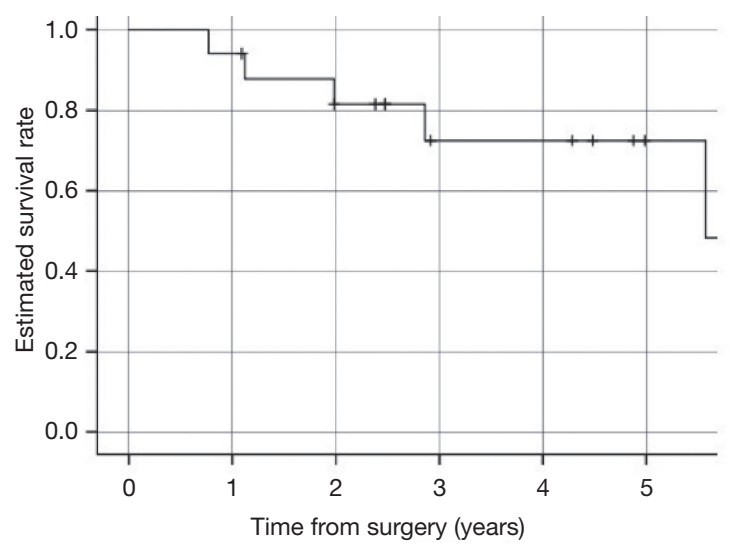

C

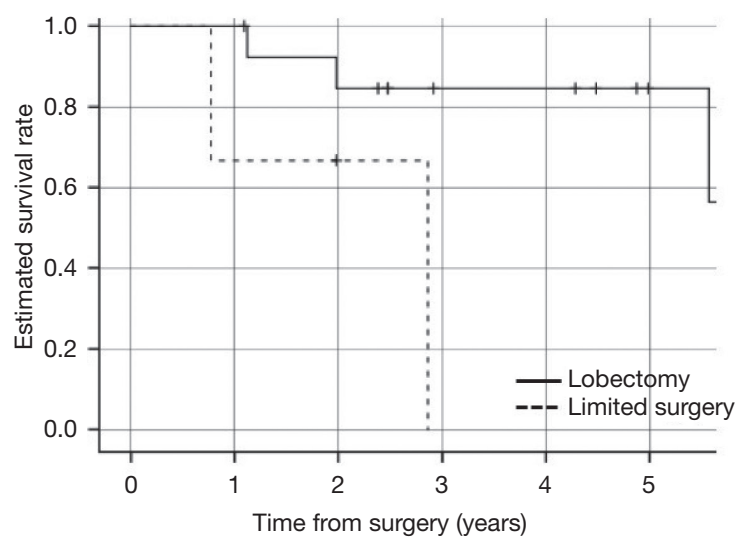

B

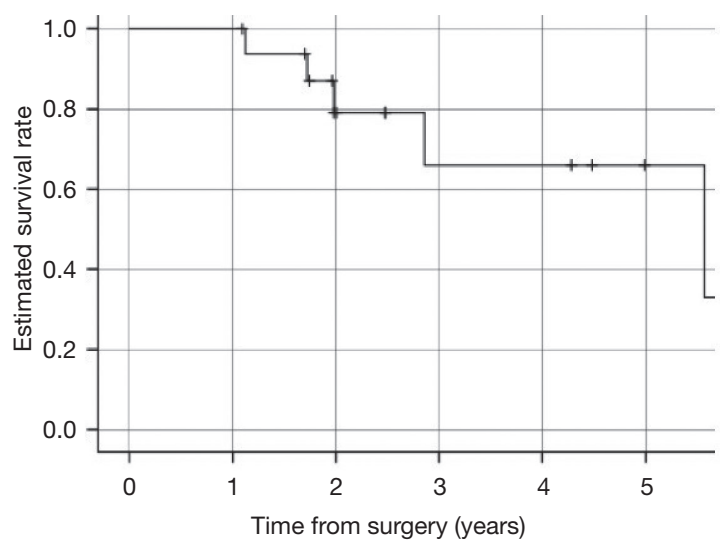

D

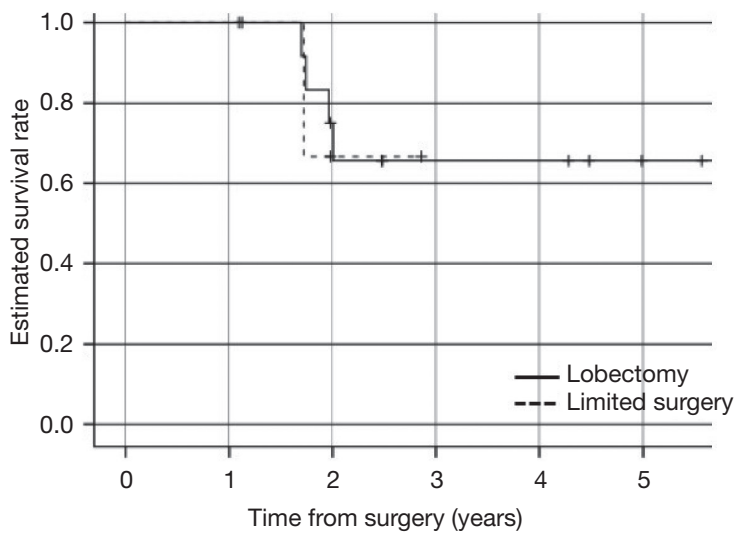

Figure 2 Overall survival (A) and disease-free survival (B) curves for patients who underwent salvage surgery after SBRT. Overall survival (C) and disease-free survival (D) curves for patients who underwent salvage surgery after SBRT, comparing the lobectomy and limited surgery. SBRT, stereotactic body radiotherapy.

often selected for treatment in high-risk patients with comorbidities or poor pulmonary function. Limited surgery has a minimal effect on pulmonary function, and if a sufficient margin $(\geq 1 \mathrm{~cm})$ of the tumor diameter can be secured, it is considered safe and effective (18). Ginsberg et al. (19) reported that the locoregional recurrence rate after wedge resection was three-fold higher than lobectomy, with poor prognosis. In addition, Crabtree et al. (13) compared local recurrence after surgery with that after SBRT, demonstrating that SBRT was associated with higher local recurrence rates. Further, Yerokun et al. (20) compared the OS after limited surgery with SBRT, and revealed that SBRT was associated with a significantly poorer prognosis; this tendency was more pronounced in elderly patients or those with comorbidities. Because SBRT may be selected in the absence of careful consideration, lobectomy and mediastinal lymph node dissection should be performed in medically operable patients.

Some reports have stated that local recurrence during follow-up after SBRT defined as continuous increase of the tumor in size or increase FDG avidity (6-8). But, one of the issues with recurrent lung cancer after SBRT is the difficulty to correctly diagnose recurrence based on imaging. Fibrotic changes often develop after SBRT and tumor shadow becomes indistinguishable from the fibrotic shadow (21). Ogawa et al. (22) reported positive FDG-PET (SUVmax $\geq 5$ ) finding does not necessarily indicate tumor recurrence because they experienced a number of false positive cases. It has been reported that late fibrotic changes or mass-like fibrosis can occur over more than two years and 
is considered to be a normal change following $\operatorname{SBRT}(9,23)$, possible delaying the recurrence diagnosis. Therefore there are no criteria to diagnose recurrence after SBRT in primary lung cancer. We defined local recurrence after SBRT as continuous increase of the tumor in size. Further, we found that the increase in tumor size ranged from 23 [12-48] to 38 [15-55] $\mathrm{mm}$. And, we defined the time period from SBRT to salvage surgery as from the start of SBRT to the date of salvage surgery. We found the time period from SBRT to salvage surgery ranges 17.3 (7.6-58.3) months. This result was similar to previous report (range between 10 and 17 months) (6-8). Careful follow-up is important to detect disease progression and to implement timely intervention.

We found stage progression in seven out of 19 patients who underwent salvage surgery $(36.8 \%)$. Other reports have shown variable results in terms of stage progression; Antonoff et al. (6) reported stage progression in 11 out of 15 patients (73.3\%) and Hamaji et al. (9) in 6 out of 12 patients $(50 \%)$, with some patients requiring additional treatment with an anticancer drug. In some cases, salvage surgery could be performed during recurrence following SBRT. Considering cancer stage progression and advancing age, SBRT must be avoided in the absence of careful consideration.

The 5 -year OS rate of $72.5 \%$ found in the present study was lower than that of $79.5 \%$ in the report by Hamaji et al. (9). The reason was thought to be that there are some cases of death from other diseases in the present study, but this comparison is unconfirmed due to the small number of cases analyzed.

The primary limitations of the present study include its retrospective design and small sample size. However, considering available literature regarding local recurrence after SBRT in patients with primary lung cancer, the sample size of 19 patients used here is the largest reported to-date. Further, there was no pathology diagnosis before SBRT in $42.5 \%$ of the cases, which may have contributed to low local recurrence rate following SBRT.

\section{Conclusions}

We evaluated patients who underwent salvage surgery to treat local recurrence of lung cancer following SBRT. Salvage surgery could be performed safely without affecting SBRT outcomes. In cases of complete resection, salvage surgery can lead to good long-term prognosis. Our evaluation suggested that SBRT was selected in medically operable patients without careful consideration. The standard treatment for patients with stage I NSCLC is lobectomy and mediastinal lymph node dissection. To provide optimal assessment and treatment, careful consideration by a multidisciplinary tumor board is required. Because of the recurrence rate following SBRT, unknown long-term outcomes, and stage progression during recurrence, we recommend that cursory SBRT selection should be avoided.

\section{Acknowledgments}

Funding: None.

\section{Footnote}

Reporting Checklist: The authors have completed the STROBE reporting checklist. Available at http://dx.doi. org/10.21037/jtd-20-2253

Data Sharing Statement: Available at http://dx.doi. org/10.21037/jtd-20-2253

Peer Review File: Available at http://dx.doi.org/10.21037/jtd20-2253

Conflicts of Interest: All authors have completed the ICMJE uniform disclosure form (Available at http://dx.doi. org/10.21037/jtd-20-2253). The authors have no conflicts of interest to declare.

Ethics Statement: The authors are accountable for all aspects of the work in ensuring that questions related to the accuracy or integrity of any part of the work are appropriately investigated and resolved. This study protocol complied with the Declaration of Helsinki (as revised in 2013) and was approved by the institutional review board at Nishi-Niigata Chuo National Hospital (approval No.1909). The requirement for informed consent was waived because all data in this study were completely anonymized.

Open Access Statement: This is an Open Access article distributed in accordance with the Creative Commons Attribution-NonCommercial-NoDerivs 4.0 International License (CC BY-NC-ND 4.0), which permits the noncommercial replication and distribution of the article with the strict proviso that no changes or edits are made and the original work is properly cited (including links to both the 
formal publication through the relevant DOI and the license). See: https://creativecommons.org/licenses/by-nc-nd/4.0/.

\section{References}

1. Baumann P, Nyman J, Hoyer M, et al. Outcome in a prospective phase II trial of medically inoperable stage I non-small-cell lung cancer patients treated with stereotactic body radiotherapy. J Clin Oncol 2009;27:3290-6.

2. Timmerman R, Paulus R, Galvin J, et al. Stereotactic body radiation therapy for inoperable early stage lung cancer. JAMA 2010;303:1070-6.

3. Taremi M, Hope A, Dahele M, et al. Stereotactic body radiotherapy for medically inoperable lung cancer: prospective, single-center study of 108 consecutive patients. Int J Radiat Oncol Biol Phys 2012;82:967-73.

4. Robinson CG, DeWees TA, El Naqa IM, et al. Patterns of failure after stereotactic body radiation therapy or lobar resection for clinical stage I non-small-cell lung cancer. J Thorac Oncol 2013;8:192-201.

5. Allibhai $Z$, Taremi M, Bezjak A, et al. The impact of tumor size on outcomes after stereotactic body radiation therapy for medically inoperable early-stage nonsmall cell lung cancer. Int J Radiat Oncol Biol Phys 2013;87:1064-70.

6. Antonoff MB, Correa AM, Sepesi B, et al. Salvage pulmonary resection after stereotactic body radiotherapy: A feasible and safe option for local failure in selected patients. J Thorac Cardiovasc Surg 2017;154:689-99.

7. Chen F, Matsuo Y, Yoshizawa A, et al. Salvage lung resection for non- small cell lung cancer after stereotactic body radiotherapy in initially operable patients. J Thorac Oncol 2010;5:1999-2002.

8. Neri S, Takahashi Y, Terashi T, et al. Surgical treatment of local recurrence after stereotactic body radiotherapy for primary and metastatic lung cancers. J Thorac Oncol 2010;5:2003-7.

9. Hamaji M, Chen F, Matsuo Y, et al. Treatment and prognosis of isolated local relapse after stereotactic body radiotherapy for clinical stage i non-small-cell lung cancer importance of salvage surgery. J Thorac Oncol 2015;10:1616-24.

10. Dindo D, Demartines N, Clavien PA. Classification of surgical complications: a new proposal with evaluation in a cohort of 6336 patients and results of a survey. Ann Surg2004; 240: 205-13.
11. Senthi S, Lagewaard FJ, Haasbeek CJ, et al. Patterns of disease recurrence after stereotactic ablative radiotherapy for early stage non-small-cell lung cancer- a retrospective analysis. Lancet Oncol 2012;13:802-9.

12. Lagerwaard FJ, Verstegen NE, Haasbeek CJ, et al. Outcomes of stereotactic ablative radiotherapy in patients with potentially operable stage I non-small cell lung cancer. Int J Radiat Oncol Biol Phys 2012;83:348-53.

13. Crabtree TD, Puri V, Robinson C, et al. Analysis of first recurrence and survival in patients with stage I nonsmall cell lung cancer treated with surgical resection or stereotactic radiation therapy. (discussion 1191) J Thorac Cardiovasc Surg 2014;147:1183-91.

14. Fernandez FG, Kosinski AS, Burfeind W, et al. The Society of Thoracic Surgeons Lung Cancer Resection Risk Model: higher quality data and superior outcomes. Ann Thorac Surg 2016;102:370-7.

15. Masuda M, Okumura M, Doki Y. Thoracic and cardiovascular surgery in Japan during 2014 : Annual report by The Japanese Association for Thoracic Surgery. Committee for Scientific Affairs, The Japanese Association for Thoracic Surgery. Gen Thorac Cardiovasc Surg 2016;64:665-97.

16. Ricardi U, Badellino S, Filippi AR. Stereotactic body radiotherapy for early stage lung cancer: History and updated role. Lung Cancer 2015;90:388-96.

17. Videtic GMM, Donington J, Giuliani M. Stereotactic body radiation therapy for early- stage non-small cell lung cancer: Executive Summary of an ASTRO Evidence-Based Guideline. Pract Radiat Oncol 2017;7:295-301.

18. Donington J, Ferguson M, Mazzone P, et al. American College of Chest Physicians and Society of Thoracic Surgeons consensus statement for evaluation and management for high-risk patients with stage I non-small cell lung cancer. Chest 2012;142:1620-35.

19. Ginsberg RJ, Rubinstein LV. Randomized trial of lobectomy versus limited resection for T1 N0 non-small cell lung cancer. Lung Cancer Study Group. Ann Thorac Surg 1995;60:615-22.

20. Yerokun BA, Yang CJ, Gulack BC, et al. A national analysis of wedge resection versus stereotactic body radiation therapy for stage IA non-small cell lung cancer. J Thorac Cardiovasc Surg 2017;154:675-686.e4.

21. Takenaka R, Shibamoto Y, Miyakawa A, et al. The fate of residual tumor masses that persist after stereotactic body radiotherapy for solitary lung nodules: will they recur? Clin Lung Cancer 2016;17:406-11. 
22. Ogawa Y, Shibamoto Y, Hashizume C, et al. Repeat stereotactic body radiotherapy (SBRT) for local recurrence of non-small cell lung cancer and lung metastasis after first SBRT. Radiat Oncol 2018;13:136

Cite this article as: Koizumi T, Aoki T, Saito M, Yamato Y, Furuyashiki G, Kitahara A, Hashimoto T, Watanabe T, Tsuchida M; for the Niigata Chest Surgery Research Group.Salvage surgery to treat tumor regrowth after stereotactic body radiotherapy in primary non-small cell lung cancer. J Thorac Dis 2020;12(10):5289-5298. doi: 10.21037/jtd-202253
23. Dahele M, Palma D, Lagerwaard F, et al. Radiological changes after stereotactic radiotherapy for stage I lung cancer. J Thorac Oncol 2011;6:1221-8. 